\title{
Effects of associative reaction time and spaced presentations of stimulus-test items, response- test items, and stimulus-response repetitions on retention in paired associate learning
}

\author{
EDWARD W. C. McALLISTER \\ Russell Sage College, Troy, New York 12180
}

\begin{abstract}
The present experiment tested the hypothesis that associative reaction time (RT, the time elapsing between the presentation of a verbal unit and the first association produced) is a variable independent of meaningfulness in PAL. This hypothesis was tested by investigating the effects of short-latency and longlatency RT lists matched for meaningfulness with spaced test items of three types (stimulus-test items, response-test items, and stimulus-response repetitions) on a recall retention test. The analysis showed that the test-type factor showed significant differences for the long-latency RT list but not the short-latency RT list. The short-latency RT list showed a significant spacing effect with retention decreasing over spacing, while the long-latency list showed no significant spacing effect. It was concluded that associative reaction time is a factor independent of meaningfulness.
\end{abstract}

Recent studies have shown that associative reaction time (RT, the time elapsing between the presentation of a verbal unit and the first association produced) is a variable of importance in paired associate learning (PAL). Ley and Locascio (1970a) found that, within groups of response terms, short-latency CVCVC terms are learned in fewer trials than long-latency terms and that the effect of RT on learning rate was limited to relatively brief presentation rates. Ley and Locascio $(1970 b, c)$ found evidence supporting the hypothesis that, within levels of meaningfulness (M), the effect of RT in PAL is limited to the term of the PA which is required to be recalled. They further presented data to indicate that the roles of RT and $M$ in PAL are different. These studies led Ley and Locascio (1971) to suggest a modification of the two-stage analysis of PAL so that recognition and recall are viewed as indicants of two separate memory processes rather than as two indicants of a single memory process. If $M$ and RT are indeed independent, as suggested by Ley and Locascio, such results ought to appear in other PAL investigations. McAllister and Ley (1972) and McAllister (1973) found that for high-meaningfulness PA word pairs delayed presentation of test items (stimulus-term test items, response-term test items, and stimulusresponse pairs) resulted in better recall than immediately presented test items. In addition, repetitions resulted

Requests for reprints should be sent to Edward McAllister, Department of Psychology, Russell Sage College, Troy, New York 12180. This experiment was supported in part by a Russell Sage College research grant and special thanks are extended to Donna Spirakos for her contribution in this experiment. This paper is sponsored by Ronald Ley, who takes full editorial responsibility for its contents. in greater retention than stimulus-term test items; and the stimulus-term test items resulted in greater retention than the response-term test items. If RT is independent of $\mathrm{M}$ in recall tasks, as Ley and Locascio (1971) suggest, would differences exist in a PAL task with spaced test items of short- and long-latency RT but equated for $\mathrm{M}$ ?

\section{METHOD}

\section{Subjects}

The subjects were 108 undergraduate volunteers from Russell Sage College. All subjects were female, enrolled in psychology courses, and between 18 and 21 years of age.

\section{Materials and Apparatus}

Lists of PAs were presented to the subjects using a Kodak Carousel Model 800 slide projector with an internal timer.

Two lists of PAs were prepared for the long-latency RT condition and also for the short-latency RT condition. In each of the four lists, there were 20 PAs that were in common and each PA was located in the same position in the list. These PAs were used to allow the structuring of the PAs that were to be tested. Two sets of 15 PAs were prepared for the shortlatency RT condition. The same 15 stimulus terms and 15 response terms were used but they were arranged to make two different PA lists. The position of the stimulus term in the master list was fixed, so the response terms of these PAs were in a different location in each of the two lists. Two sets of PAs were prepared for the long-latency RT condition in like manner. The stimulus terms were the same as for the short-latency RT lists, since research indicates that only the response terms are affected by RT. Therefore, if one looked at the stimulus terms only in the lists, the four lists would be identical. If one looked at the response terms, there would be two different lists based on RT and each of these lists would have two different forms based on order.

The CVCVC response terms used for the 15 PAs under study were selected in pairs such that they were as equal as possible in meaningfulness (rated association frequency, $a^{\prime}$, and scaled rated association frequency, $\mathrm{m}^{\prime}$ ) and as different 
as possible in associative reaction time (RT, mean latency in seconds). The CVCVC response terms in the long-latency list had mean values of $\mathrm{a}^{\prime}=3.64, \mathrm{~m}^{\prime}=3.38, \mathrm{RT}=2.81$; and the CVCVC response terms in the short-latency list had mean values of $\mathrm{a}^{\prime}=3.64, \mathrm{~m}^{\prime}=3.34, \mathrm{RT}=1.98(\mathrm{RT}$ was determined by Taylor \& Kimble, 1967; $a^{\prime}$ and $m^{\prime}$ by Locascio \& Ley, 1972). The difference between mean values for RT was statistically significant, $\mathrm{t}=7.33, \mathrm{p}<.01$.

The 15 differing PA terms in each list received repetitions or test items spaced into the list during the learning trial. The repetitions, stimulus-test items, or response-test items were spaced within the list of zero, two, four, six, and eight PA terms. There were three PA terms in each list receiving each spacing interval. Each treatment list was, therefore, made up of the 35 PA terms and 15 appropriately spaced repetitions or test items (three for the zero-item interval, three for the two-item interval, three for the four-item interval, three for the six-item interval, and three for the eight-item interval), for a total of 50 slides in each treatment. The long-latency and short-latency RT lists were identical in regard to all the stimulus CVCVCs.

The slides were constructed by making Xerox transparencies of typed lists, cutting them to fit $35-\mathrm{mm}$ slide mounts, and mounting them in Kodak $35-\mathrm{mm}$ cardboard mounts.

After the subjects had completed their PAL task, they were given a standard symbol cancellation task (Runquist, 1966), a paper and pencil task in which subjects were directed to cross out certain symbols in all rows.

The final retention test was constructed by listing all the stimulus CVCVCs from the PA lists and leaving blanks for all the response terms.

\section{Procedure}

Each of the 108 subjects was assigned to one of the six treatment groups, so that there were an equal number of subjects in each group $(n=18)$. The treatment groups were defined by one of three types of spacing tests (repetitions, stimulus-test items, and response-test items) and one of the two levels of RT latencies (short or long). In each of the six treatment groups, each subject was given five spacing intervals.

In any given treatment, 15 slides were spaced test items (the subject was required to write in the missing CVCVC) without feedback or repetitions of PA terms already seen. In this way, three different PA terms received a repetition or test item without feedback at each of the five spacing intervals. The material was presented to the subjects for one round (50 slides) at a 7-sec presentation rate, with $1 \mathrm{sec}$ to change slides.

When the subjects arrived at the laboratory, they were assigned seats, each of which provided a clear view of the screen. Each subject was given a standard copy of the PAL instructions which the experimenter read aloud to them. The instructions informed the subjects of the nature of the PAL task, the apparatus to be used, and a sample of the materials that were to be presented.

At the completion of the PAL task, the subjects were given the symbol cancellation task for $10 \mathrm{~min}$, after which the subjects were given the recall retention test. The total time for the application of the treatment was about $35 \mathrm{~min}$. Treatments were carried out over a 4-week period.

\section{RESULTS}

A three-factor mixed ANOVA was used in which the two between-subject variables were test-item type (stimulus-test items, response-test items, or repetitions) and RT (short- and long-latency), and the within-subject
Table 1

Mean Transformed Retention Scores $(X=\operatorname{arc} \sin X)$ for Each of Six Treatment Groups at Each of Five Spacing Intervals

\begin{tabular}{ccccccc}
\hline \multirow{2}{*}{$\begin{array}{c}\text { Spacing } \\
\text { Interval }\end{array}$} & \multicolumn{2}{c}{ Stimulus-Test } & \multicolumn{2}{c}{ Response-Test } & \multicolumn{2}{c}{ Repetitions } \\
in PA & S-L & L-L & S-L & L-L & S-L & L-L \\
Terms & RT & RT & RT & RT & RT & RT \\
\hline 0 & 22.88 & 20.38 & 25.71 & 14.92 & 32.56 & 25.77 \\
2 & 28.39 & 22.59 & 29.88 & 19.84 & 25.91 & 38.70 \\
4 & 28.98 & 25.34 & 27.59 & 23.42 & 35.68 & 34.48 \\
6 & 14.60 & 19.56 & 11.85 & 25.95 & 15.74 & 35.87 \\
8 & 13.78 & 19.60 & 24.52 & 23.42 & 30.68 & 48.62 \\
\hline
\end{tabular}

Note $-S-L=$ short latency, $L-L=$ long latency

variable was spacing interval (zero, two, four, six, or eight PA terms).

The mean recall retention scores for all treatment groups under all conditions are given in Table 1. All scores were transformed $\left(X^{\prime}=\operatorname{arc} \sin \sqrt{ } X\right)$ to better meet the assumptions of ANOVA. Such a transformation is suggested by Myers (1969).

Consistent with the findings of McAllister and Ley (1972) and McAllister (1973), the effect of spacing interval on retention was significant, $F(4,408)=2.93$, $\mathrm{p}<.05$. Overall there was no significant difference between the recall of short- and long-latency response terms, $F(1,102)=.40, p>.05$. However, the Spacing Interval by RT interaction was found to be significant, $\mathrm{F}(4,408)=4.05, \mathrm{p}<.005$. This interaction is shown in Figure 1. This figure shows that the retention for short-latency response terms is greater than the retention for long-latency response terms for the shorter spacing intervals, but the relationship reverses for the longer spacing intervals.

The test-type variable was also significant, $F(2,102=$ $4.51, \mathrm{p}<.025$. This finding also was in agreement with the findings of McAllister and Ley (1972) and McAllister (1973). Further analysis revealed that, whereas the test-type factor (stimulus-test item, response-test item, or repetition) showed a significant difference for the long-latency RT list, $F(2,51)=4.94$, $\mathrm{p}<.025$, there were no significant differences between

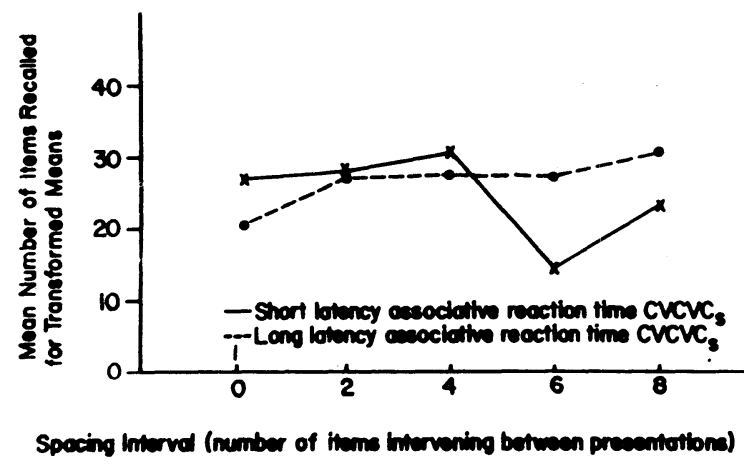

Figure 1. Mean number of PAs recalled for each of five spacing intervals for short-latency and long-latency associative RT CVCVC response terms. 


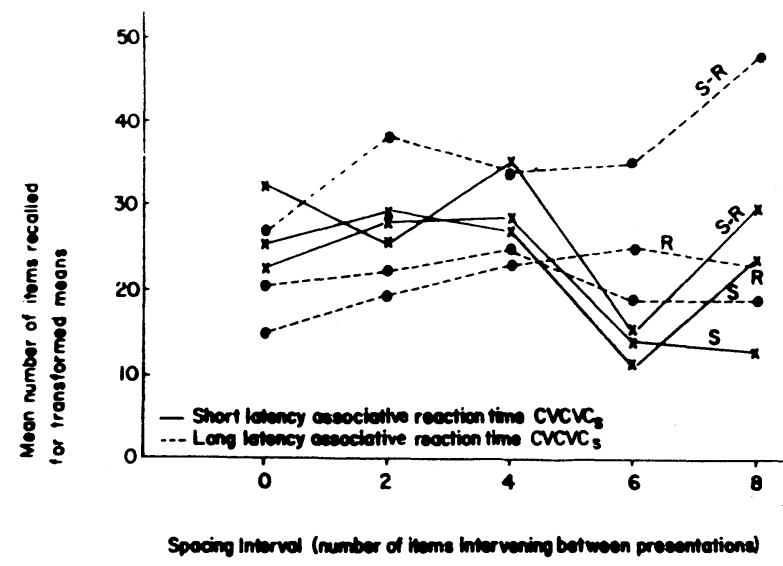

Figure 2. Mean number of PAs recalled for each of five spacing intervals and each of three test item types for shortlatency and long-latency associative RT CVCVC response terms.

the test types for the short-latency RT list, $F(2,51)=$ $1.86, \mathrm{p}>.05$. For the long-latency RT list, repetitions were clearly superior to test items.

The spacing effect was limited to the short-latency RT list, $F(4,204)=4.77, p<.001$. For the long-latency list no spacing effect was present, $F(4,204)=1.87$, $\mathrm{p}>.05$.

\section{DISCUSSION}

Clearly, associative RT is a variable of importance in PAL separate from meaningfulness as suggested by Ley and Locascio (1970c, 1971). This confirmation of their findings is particularly meaningful since it comes from a different experimental paradigm. For short-latency RT response-term lists, there was no test-type effect, but there was a spacing effect. For longlatency RT response-term lists, there was a test-type effect but no spacing effect. Ley and Locascio (1971) cite Tulving (1966) and Glanzer and Meinzer (1967), who found that overt repetition of items resulted in poorer recall than "silent rehearsal." They posed the question as to what subjects do during silent rehearsal. The results of this study indicate that RT may be a determining factor as to the kind of rehearsal the subjects use during the learning trial. RT measures time required to make an association. If recall is a function of making an association to the to-be-recalled verbal unit, then shortlatency units should be recalled more frequently than longlatency units. Therefore, the generally less effective stimulusand response-test items are as effective as the repetitions for the short-latency terms but not for the long-latency terms. The effect shows itself in Figure 2.

However, the short-latency RT terms show a spacing effect, with the longer spaced items showing inferior retention to the shorter spacings. The long-latency RT terms did not show a significant spacing effect, but all the spacing intervals were slightly higher than the massed intervals (see Figure 1). It appears that two kinds of encoding processes may be in operation. Since associations are made rapidly with the shortlatency RT terms, the rehearsal of these terms may be more of a rote process and not result in the stable encoding that would be required for the retention test. The long-latency RT response terms, on the other hand, may necessitate a different kind of encoding that relies more on memory processes after the subject has come up with an association. The clear superiority of the repetition condition of the long-latency RT response term would support this concept. In short, then, it appears that the associative RT of the response terms to be recalled may be the factor that triggers a differential encoding process that influences the effect of both test-item types and the spacing interval in PAL.

\section{REFERENCES}

Glanzer, H., \& Meinzer, A. The effects of intralist activity on free recall. Journal of Verbal Learning and Verbal Behavior, 1967, 6, 929-935.

LEY, R., \& Locascio, D. Associative reaction time and meaningfulness of CVCVC response terms in paired associate learning. Journal of Experimental Psychology, 1970, 83, 445-450. (a)

LEY, R., \& Locascio, D. Effects of associative reaction time and meaningfulness of stimulus terms in forward and backward paired associate learning. Psychological Reports, 1970 , 27, 867-873. (b)

LEY, R., \& LocAscio, D. Effects of familiarization, associative reaction time, and meaningfulness of response terms in forward and backward paired associate learning. Psychonomic Science, 1970, 21. 97-99. (c)

LEY, R., \& Locascio, D. Subject generated and experimental supplied associations to words and paralogs in cued recall. Paper presented at the Psychonomic Society meeting, St. Louis. Missouri, 1971.

Locascio, D., \& LEY, R. Scaled-rated meaningfulness of 319 CVCVC words and paralogs previously assessed for associative reaction time. Journal of Verbal Learning and Verbal Behavior, 1972, 11, 108-115.

McAllister. E. W. C. Effects of type of recall test and spaced presentations of stimulus terms, response terms, and stimulus response terms on retention in paired associate learning. Psychological Reports, 1973, 33, 307-311.

Mc Allister, E. W. C., \& LEY, R. Effects of spaced presentation of stimulus terms, response terms, and stimulus-response pairs on retention in paired associate learning. Journal of Experimental Psychology, 1972, 94, 68-73.

MyERS, J. L. Fundamentals of experimental design. Boston: Allyn and Bacon, 1969. P. 65.

RunQuist, W. N. Verbal behavior. In J. B. Sidowski (Ed.), Experimental methods and instrumentation in psychology. New York: McGraw-Hill, 1966. Pp. 487-540.

TAYlor, J. D., \& Kimble, G. A. The association value of 320 selected words and paralogs. Journal of Verbal Learning and Verbal Behavior, 1967, 6, 744-752.

Tulving, E. Subjective organization and effects of repetition in multitrial free-recall learning. Journal of Verbal Learning and Verbal Behavior, 1966, 5, 193-197.

(Received for publication September 29, 1975.) 